\title{
FABRICATION AND CHARACTERIZATION OF FAST DISSOLVING FILMS OF ECLIPTA PROSTRATE LEAVES EXTRACT TO TREAT MOUTH ULCERS
}

\section{S. S. MANIKIRAN ${ }^{1}$, NAGAM SANTHI PRIYA ${ }^{1}$, B. AUBINE MOLLY ${ }^{2}$, LAKSHMI PRASANTHI NORI ${ }^{3 *}$}

1Department of Pharmaceutics, Vignan Pharmacy College, Vadlamudi, ${ }^{2}$ Acharya Nagarjuna University, Nagarjuna Nagar, Guntur, 3Department of Pharmaceutical Sciences, Vignan's Foundation for Science Technology and Research, Vadlamudi Email: prasanthi_pharm@yahoo.com

Received: 25 Mar 2021, Revised and Accepted: 19 Jun 2021

\section{ABSTRACT}

Objective: This research focused on the design of fast dissolving herbal film of Eclipta Prostrate leaves extract for mouth ulcers.

Methods: The extract of Eclipta Prostrata leaves was formulated as films by solvent casting method using various polymers viz., HPMC E5, HPMC E15, sodium alginate and PVA. The films were designed by using propylene glycol as a plasticizer, SSG as super disintegrate and honey as a sweetener. Furthermore, the films were evaluated for thickness, folding endurance, weight variation, $\%$ elongation, surface $\mathrm{pH}, \% \mathrm{moisture}$ uptake, $\%$ moisture loss, disintegration and in vitro drug release study.

Results: The revealed that all the films were good in appearance and had a smooth texture. Out of all ten formulations, F3 and F5 disintegrated rapidly with a disintegration time of 27 and 32 seconds. The drug release studies revealed that all the formulations had a good release profile, but the F3 formulation showed rapid release i.e. 83.57\% in $4 \mathrm{~min}$. The stability studies revealed that the formulations F3 and F5 were found good with non-tackiness, easily separable and disintegrated at 29 and $33 \mathrm{sec}$ respectively with no appearance and drug release.

Conclusion: The research revealed that Eclipta prostrate leaves extract can be formulated into oral films for the treatment of mouth ulcers with improved bioavailability and expected patient compliance.

Keywords: Eclipta prostrate, Extract, Oral films, Super disintegrants and mouth ulcer

(C) 2021 The Authors. Published by Innovare Academic Sciences Pvt Ltd. This is an open access article under the CC BY license (https://creativecommons.org/licenses/by/4.0/) DOI: https://dx.doi.org/10.22159/ijap.2021v13i5.41597. Journal homepage: https://innovareacademics.in/journals/index.php/ijap

\section{INTRODUCTION}

Administration of dosage forms through the oral route is the most convenient and suitable route. Some classes of patients are facing difficulty to take oral formulations i.e. geriatric, pediatric and dysphagia patients due to difficulty of swallowing or chewing dosage forms [1, 2]. Fast dissolving films having the ability to dissolve and disintegrate quickly in a few seconds when placed on a patient's tongue or in oral mucosa and release the drug for oromucosal or intragastric absorption. Hence, they offer a number of advantages over other solid dosage forms viz., tablets and capsules by eliminating swallowing problems and maintaining water, which leads to more patient compliance. The rapid release of the drug from the films is due to the large surface area of the film, which is exposed to the moist oral area and causing quick disintegration and dissolution in oral cavity in seconds [3, 4]. The design of oral films with herbal extract is an interesting trend.

Ulcers are lesions on the surface of the skin or mucous membrane characterized by a superficial loss of tissue. There are many varieties of ulcers such as mouth ulcer, esophagus ulcer, peptic ulcer and genital ulcer [5]. Mouth ulcers/sores are common ailments that affect many people at some point in their life cycle. The sores appear on any of the soft tissues of the mouth including lips, cheeks, gums, tongue and floor and roof of the mouth. In the period of ulcer, eating increases the pain rather than relieves the pain. The other symptoms include nausea, vomiting and weight loss [6]. At present $75-80 \%$ of the world population using herbal medicine mainly in developing countries due to cultural acceptability, compatibility and lesser side effects. Preliminary phytochemical screening of the medicinal plant Eclipta Prostrate (Asteraceae) indicated the presence of important secondary metabolites like flavonoids and tannins, which are active principles for antiulcer activity. Eclipta Prostrate is used traditionally in the Indian system of medicine as hepatoprotective, anti-inflammatory, hypoglycemic, immunomodulator and in wound healing. The plant shows significant attenuation in lipid peroxidation, superoxide dismutase activity. The antisecretory activity of the plant is evidenced by significant reduction in gastric volume, acid output and an increase in gastric $\mathrm{pH}[7,8]$.

The aim of the present investigation was to fabricate and characterize the fast dissolving film of Eclipta Prostrate leaves extract by solvent casting method with a blend of polymers viz., HPMC E5, HPMC E15, sodium alginate and PVA [9].

\section{MATERIALS AND METHODS}

\section{Materials}

Leaves of the plant Eclipta Prostrate were collected directly from the plant in and around Guntur, Andhra Pradesh, India from March to August. The plant was authenticated as Eclipta Prostrate by Dr. Ammani (Voucher specimen V 2762), Head, Department of Botany, Acharya Nagarjuna University, Guntur, Andhra Pradesh, India. The plant was deposited at the biology department of the laboratory. HPMC E15, HPMC, PVA were procured from Merck Labs, Mumbai. Sodium alginate, propylene glycol, sodium starch glycolate was from Fisher Scientific, Mumbai. Sugar was purchased from the local market. All ingredients were of pure and analytical grade.

\section{Extracting Eclipta prostrate leaves}

The fresh leaves were collected in bulk from local areas. Then the debris was removed from the collected material and dried in shade. The dried leaves were coarsely grounded in a mixer. The coarse powder was successively extracted by the soxhlation process with water. Extract was concentrated by distilling the solvent and then dried [10]. The dried extract was collected and was stored in a desiccator for further use.

\section{Phytochemical screening of the extract}

The extract was tested for the presence of various active chemical constituents namely steroids, alkaloids, tannins, phenolic compounds, flavonoids, glycosides, diterpenes, triterpenes and saponins [11, 12]. The results of the phytochemical study were given in table 1 .

\section{Preparation of fast disintegrating films}

Fast disintegrating films of Eclipta Prostrate extract were prepared by solvent casting method as per the formulae given in table 2 [13]. The films were formulated by using various polymers viz., HPMC, PVA, HPMC E15, and Sodium alginate. The required quantity of polymers and plasticizer (propylene glycol) was dissolved in double- 
distilled water. This polymeric dispersion was stirred for $1 \mathrm{~h}$ using a magnetic stirrer and kept aside for deaeration. In another beaker plant extract, super disintegrate (sodium starch glycolate) and honey was dissolved in a specific proportion of distilled water. The resulting aqueous solution was added to polymeric dispersion and stirred for $1 \mathrm{~h}$. After deaeration of the blend, it was casted on the film former apparatus (VJ Instruments, Mumbai) and temperature was maintained at $30-50{ }^{\circ} \mathrm{C}$. Dried film was carefully removed from the film-forming machine and trimmed into $3 \times 3 \mathrm{~cm}^{2}$ size. Trimmed films were stored in an airtight container and subjected for evaluation.

\section{Evaluation tests}

\section{Standard calibration curve for Eclipta prostrate leaves extract}

Accurately weighed amount of Eclipta prostrate $(10 \mathrm{mg})$ extract was dissolved in a few $\mathrm{ml}$ of water and the volume was made up to $10 \mathrm{ml}$ with water. From this stock solution aliquot of $0.2 \mathrm{ml}, 0.4 \mathrm{ml}, 0.6 \mathrm{ml}, 0.8$ $\mathrm{ml}$ and $1.0 \mathrm{ml}$ were pipetted out into a series of $10 \mathrm{ml}$ volumetric flasks and makeup to mark with water in order to get a concentration within the Beer's range from $20-100 \mu \mathrm{g} / \mathrm{ml}$. The samples were analyzed by UV spectrophotometer [14]. The process was carried out in triplicate.

\section{Antimicrobial activity}

Biological screening of plant extracts was most frequently carried out to determine the antibacterial activity. These evaluations are done by means of standard in vitro assay (agar well diffusion) utilizing a broad spectrum of pathogenic and nonpathogenic bacteria. In the present study gram-positive (S. Aureus, B. Subtilis) and gram negative (E. Coli, P. Aeruginosa) bacterial strains were used. These organisms are responsible for various minor or major infections in humans $[15,16]$.

\section{Morphological properties}

The morphological properties such as homogenous nature of films, colour, transparency and surface texture were observed visually. All the formulations were stored at room temperature $25 \pm 30{ }^{\circ} \mathrm{C}$ in airtight containers.

\section{Uniformity of film thickness}

The thickness of the films was measured by using a screw gauge at 5 different strategic locations. This helps in determining the uniformity of thickness of oral fast disintegrating films, which directly relates to the accuracy of the dose [17].

\section{Folding endurance}

Folding endurance proved the information regarding the flexibility as well as the physical ability of the films. It was measured by firmly folding films repeatedly in the middle. The number of folds required to produce crack in the film was noted as the value of folding endurance [18]

\section{Tensile strength}

Three films from each formulation were taken and cut into $5 \mathrm{~cm}$ width and $10 \mathrm{~cm}$ length. The force required to break the films was determined using tensile strength apparatus (HIKS tensile strength apparatus THE500) in triplicate. tensile strength is calculated by using the formula [19].

Tensile strength $=$ breaking force/area of cross - section

\section{Percentage elongation}

Percentage elongation provides information regarding the mechanical property of the films. When the physical force was applied on the films, it stretches, referred to as a strain. Strain causes the deformation of films by changing the original dimension of the films. The percentage elongation value increases with an increase in the plasticizer concentration. It was calculated by using the following formula [20].

$$
\text { Percentage elongation }=(\mathrm{L}-\mathrm{L} 0) / \mathrm{L} 0 * 100
$$

Where, $\mathrm{L}=$ final length, $\mathrm{L}_{0}=$ initial length

\section{Percentage moisture loss}

The percentage moisture loss studies were carried to check the film's physical stability. Initially weighed films of predetermined size $(3 \times 3$ $\mathrm{cm}^{2}$ ) were placed in a desiccator containing anhydrous calcium chloride for three days. The films were removed and weighed again to calculate the percentage moisture loss by using the following formula [21].

$\%$ Moisture loss $=(($ initial weight - final weight $) /$ initial weight $) * 100$

\section{Percentage moisture uptake}

The weighted films were kept in a desiccator at room temperature for $24 \mathrm{~h}$. The films were collected and exposed to $84 \%$ relative humidity using a saturated solution of potassium chloride in desiccators until a constant weight was achieved. The \% moisture uptake was calculated by using the formula [22]

$\%$ Moisture uptake $=(($ initial weight - final weight $) /$ initial weight $) * 100$

\section{Surface pH}

To measure the $\mathrm{pH}$ of the film, the film was cut into a square shape $\left(3 \times 3 \mathrm{~cm}^{2}\right)$ and was placed in a dish and moistened with $1 \mathrm{ml}$ of water and kept aside for $1 \mathrm{~min}$. The surface $\mathrm{pH}$ of the films was measured by using a pH meter (ELICO-LI120). The process was carried out in triplicate [23].

\section{In vitro release studies}

The release rate of the Eclipta prostrate extract from the fastdissolving films was determined by the help of USP Dissolution Test Apparatus-II. The release study was performed in $900 \mathrm{ml}$ phosphate buffer $\mathrm{pH} 6.8$, at $37 \pm 5{ }^{\circ} \mathrm{C}$ with $50 \mathrm{rpm}$ speed. Aliquot of the solution was collected and replaced with fresh medium at every 30 secs to maintain the sink conditions. The Aliquot was filtered through the Whatman's filter paper. The absorbance of the filtered solution was measured at $221 \mathrm{~nm}$. The sample should be withdrawn at the zone between the surface of the dissolution medium and the top of the rotating paddle not less than $1 \mathrm{~cm}$ apart from the vessel wall. The cumulative amount of drug release was calculated by using the calibration data [24]. The process was carried out in triplicate.

\section{Stability studies}

The optimized formulation was evaluated for stability studies by storing at $40{ }^{\circ} \mathrm{C}$ and $75 \% \mathrm{RH}$ for $3 \mathrm{mo}$. The samples were analyzed for physical appearance, disintegration time and preservative efficacy test [25].

\section{RESULTS AND DISCUSSION}

Eclipta prostrate known as bhringraj, is a famous herb widely used for hair growth, productive cough, ulcers, asthma and liver disorders. Hence, in the present investigation leaf extract of Eclipta prostrate was formulated into fast dissolving films to treat mouth ulcers [26]. The fresh leaves of Eclipta prostrate were collected in and around Guntur. They were dried by the air-drying process. The dried leaves of the Eclipta prostrate were extracted by the soxhlation process by using water as menstruum. The extract was dried and tested for phytochemical constituents. The results of the preliminary phytochemical screening revealed the presence of steroids, flavonoids, saponins, diterpenes. The data were given in table 1 .

Table 1: Phytochemical constituent's data of Eclipta prostrata extract

\begin{tabular}{ll}
\hline Active ingredient & Results* \\
\hline Steroids & Present \\
Alkaloids & Absent \\
Phenolic compounds & Absent \\
Tannins & Present \\
Flavonoids & Present \\
Glycosides & Absent \\
Diterpenes & Present \\
Triterpenes & Present \\
Saponins & Present \\
\hline
\end{tabular}

$$
*_{\mathrm{n}}=3
$$

The compatibility of an extract with the polymers was studied by using IR spectroscopic methods. The spectra were shown in fig. 1 and 2 . The spectra revealed that formulations having characteristic peaks same as that of the pure extract. It indicated that there was no interaction between drugs and excipients. 


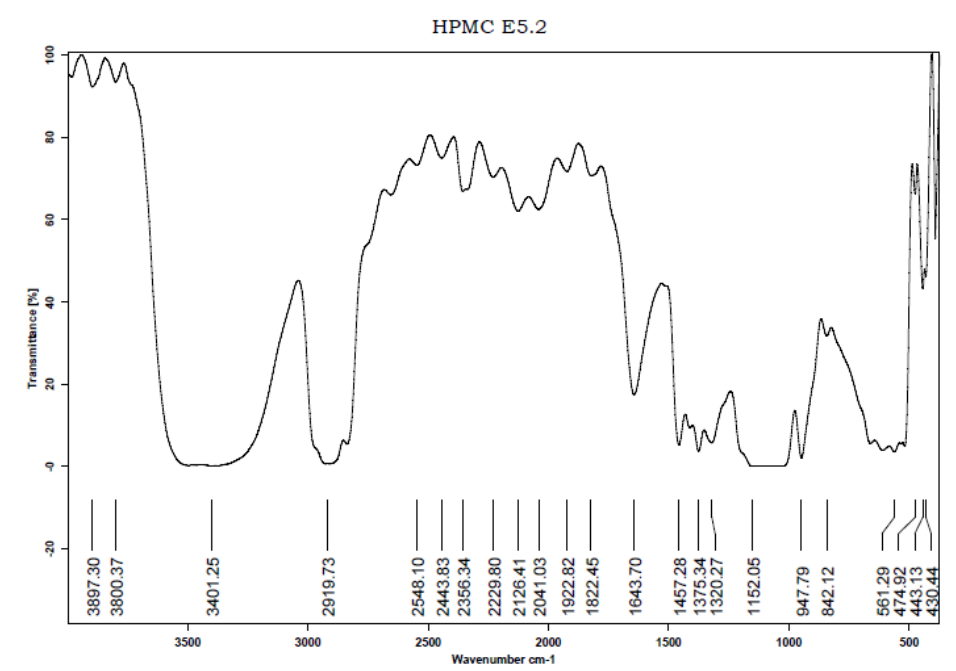

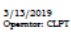

(a)

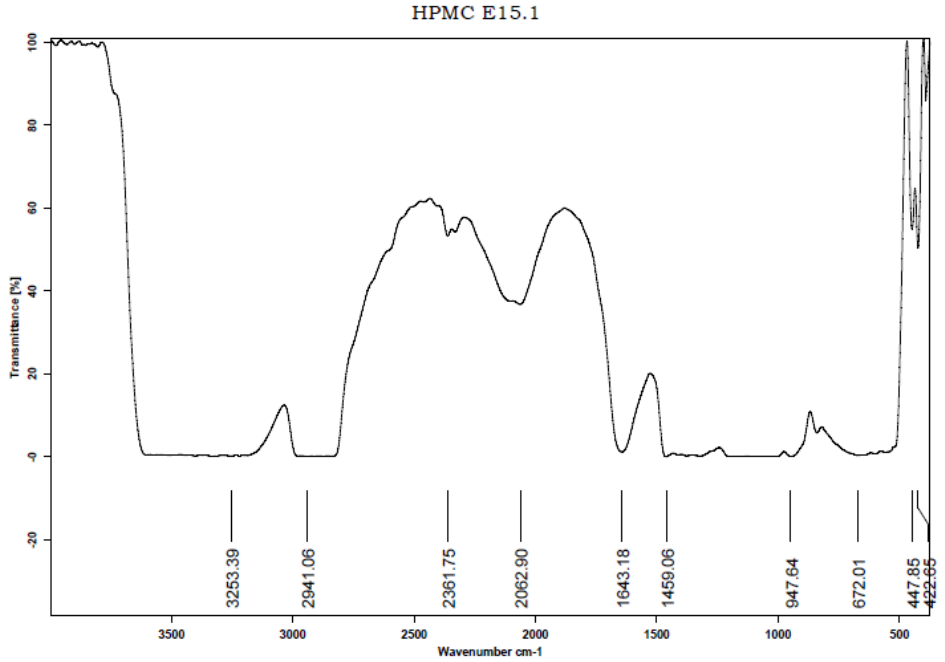

atypers

(b)

SODIUM ALGINATE.

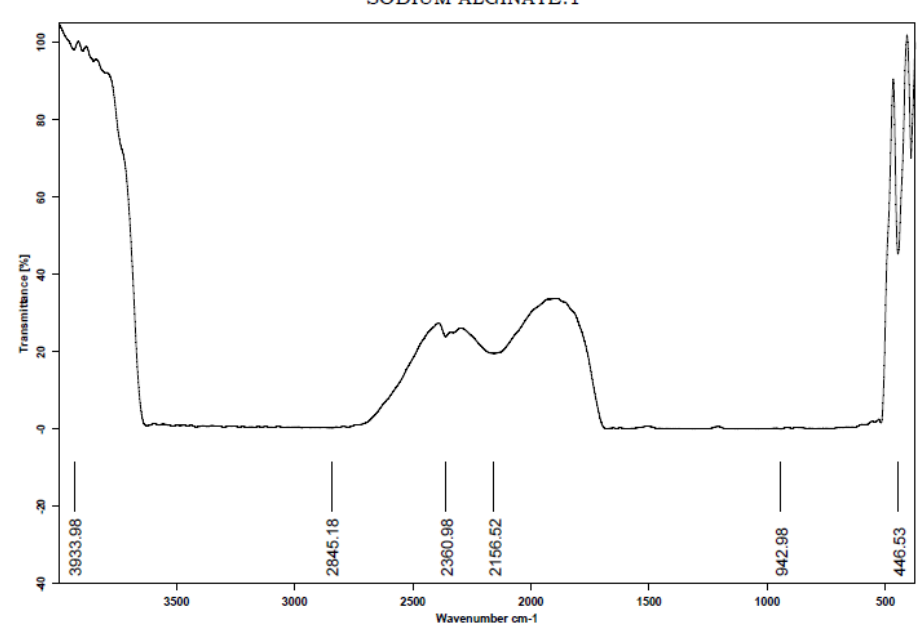

yos

(c) 


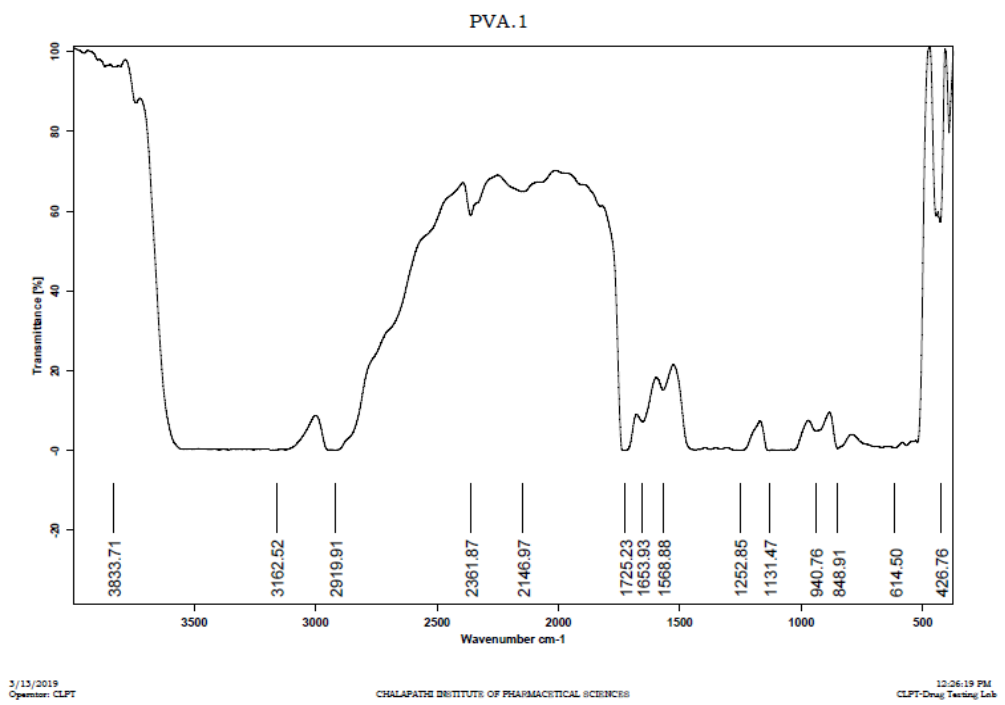

(d)

Fig. 1: FTIR spectra of a) F1 b) F2 c) F3 d) F4

HPMC E5 AND SODIUM ALGINATE AND PVA.O

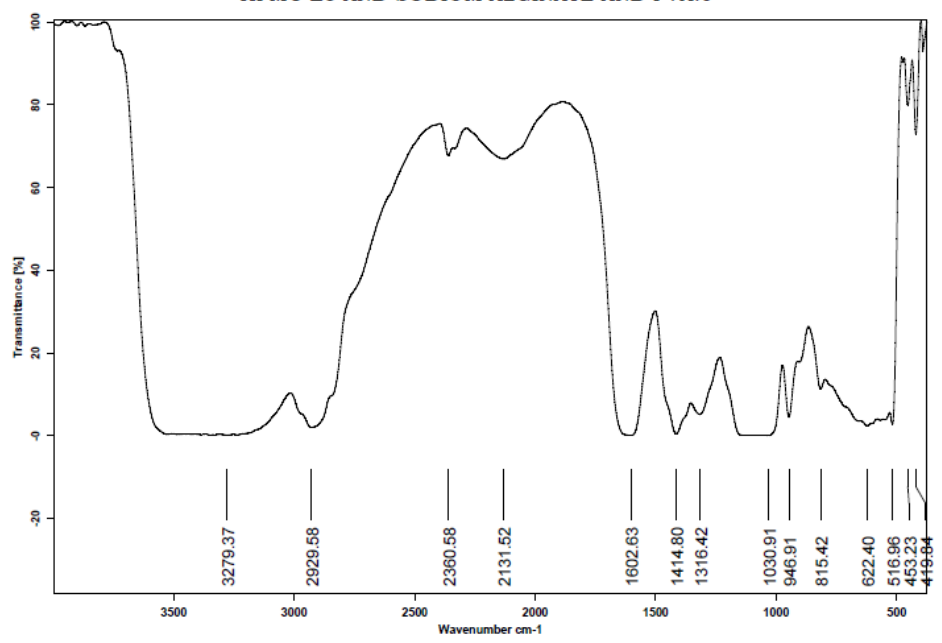

$\frac{1}{3 / 13 / 2019}$

(e)

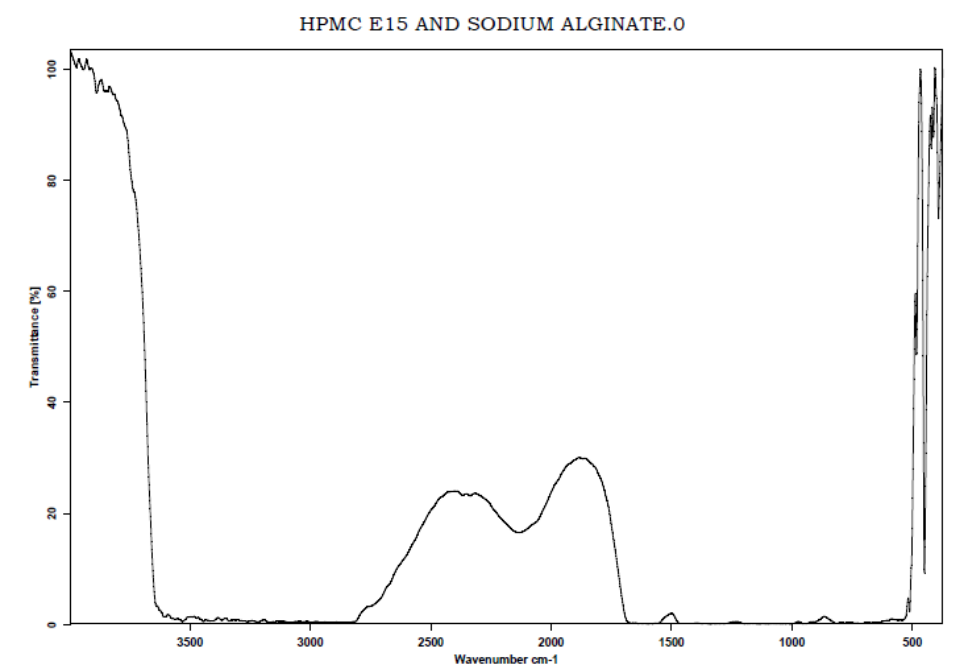

s/19/2019

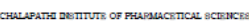

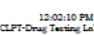

(f) 


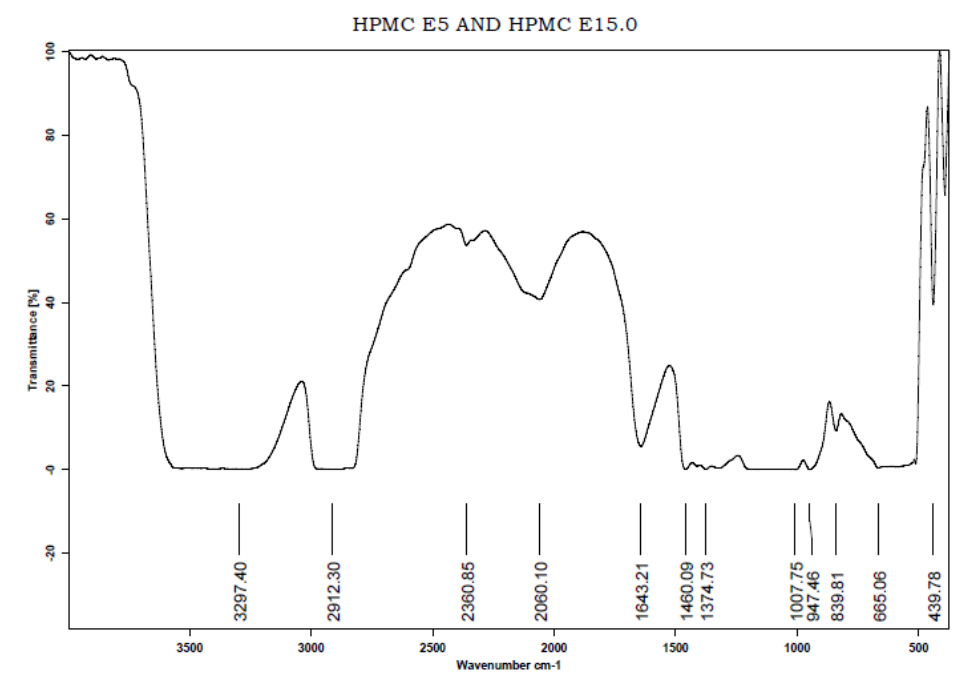

g/13/2019

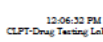

(g)

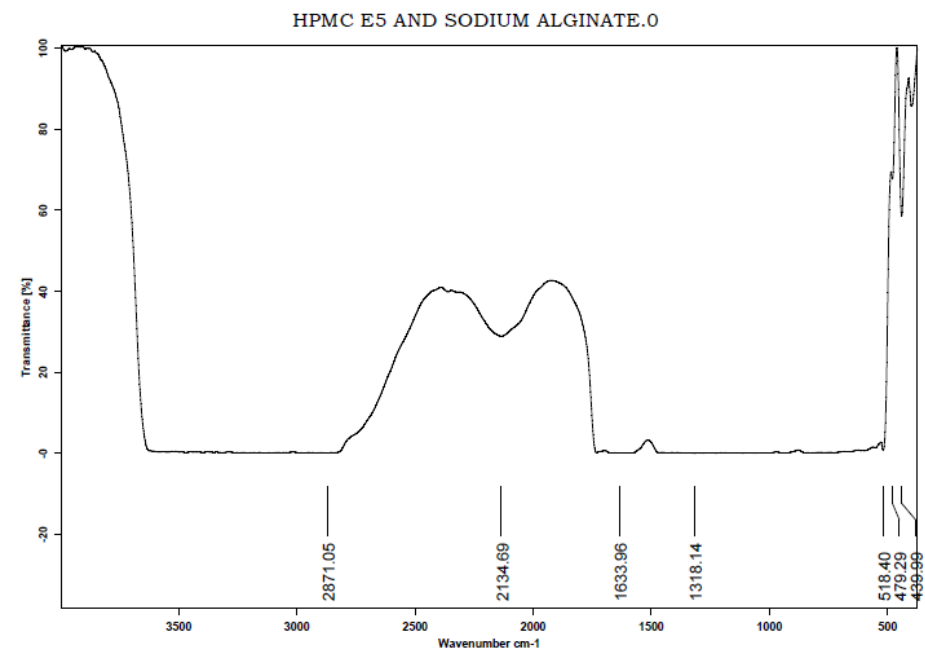

s/yprases

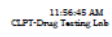

(h)

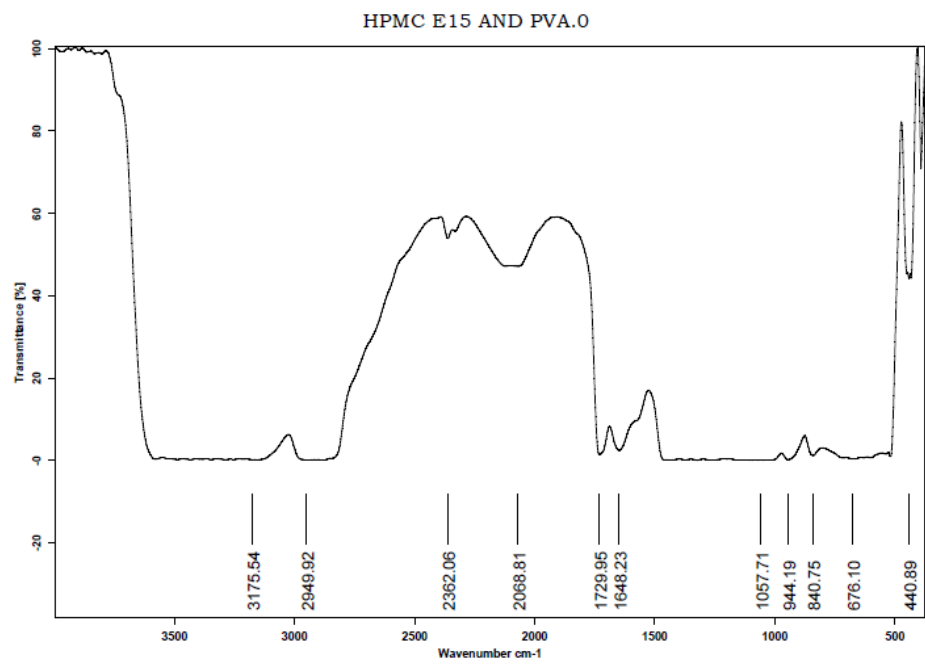

s/192019 


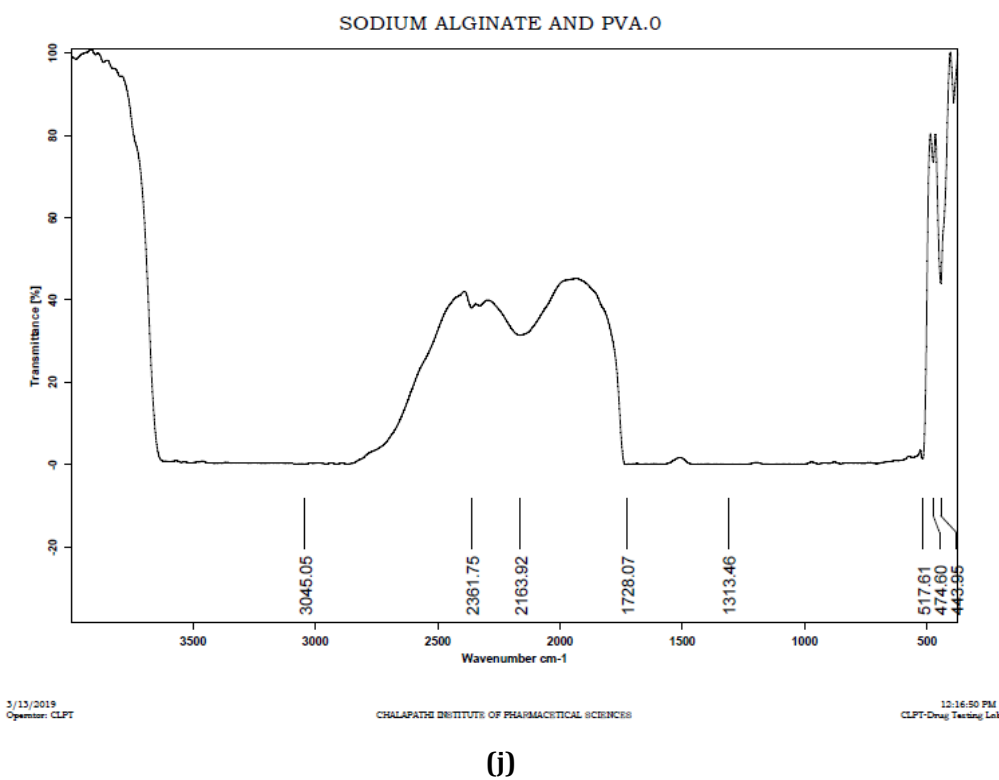

Fig. 2: FTIR spectra of formulation containing (e) F5 (f) F6 (g) F7 (h) F8 i) F9 (j) F10

The antibacterial activity of crude aqueous extract of eclipta prostrate against the pathogenic and nonpathogenic organisms was studied by agar well diffusion method. The activity was carried out at $500 \mu \mathrm{g} / \mathrm{ml}$ concentrations and by measuring the zone of inhibition
[27]. The highest antibacterial activity was exhibited against E. Coli $(16 \mathrm{~mm})$ and moderate activity against $\mathrm{S}$. aureus $(13 \mathrm{~mm})$, the data was given in table 2 . The results indicated that the extract had good antimicrobial activity.

Table 2: Antibacterial activity data of aqueous extract of Eclipta prostrate

\begin{tabular}{lll}
\hline Name of the organism & Zone of inhibition $\mathbf{~ i n ~} \mathbf{~ m m}$ & \\
\hline & Aqueousextract $\mathbf{5 0 0} \boldsymbol{\mu} \mathbf{g} \mathbf{m l}$ & Amoxicillin $\mathbf{1 0 0} \boldsymbol{\mu g} / \mathbf{m l}$ \\
\hline S. aureus & $15 \pm 0.14$ & $24 \pm 0.54$ \\
B. subtilis & $13 \pm 0.13$ & $17 \pm 0.19$ \\
E. Coli & $16 \pm 0.74$ & $23 \pm 0.87$ \\
P. aeruginosa & $13 \pm 0.27$ & $19 \pm 0.35$ \\
\hline
\end{tabular}

*values are expressed as mean $\pm \mathrm{sd}, \mathrm{n}=3$

The extract was formulated into fast dissolving films by solvent casting method with various polymers such as HPMC E5, HPMC E15, sodium alginate and PVA. Sodium starch glycolate was used as a disintegrant, propylene glycol as plasticizer and honey as a sweetening agent [28]. The films were designed as per the formulae given in table 3.

Table 3: Formulae of herbal film

\begin{tabular}{|c|c|c|c|c|c|c|c|c|c|c|}
\hline Ingredients & F1 & F2 & F3 & F4 & F5 & F6 & F7 & F8 & F9 & F10 \\
\hline Plant extract (\%) & 2 & 2 & 2 & 2 & 2 & 2 & 2 & 2 & 2 & 2 \\
\hline HPMC E5 (\%) & 4 & - & - & - & 2 & - & 2 & 2 & - & - \\
\hline HPMC E15 (\%) & - & 4 & - & - & - & 2 & 2 & - & 2 & - \\
\hline Sodium alginate (\%) & - & - & 4 & - & - & 2 & - & 2 & - & 2 \\
\hline $\operatorname{PVA}(\mathrm{ml})$ & - & - & - & 4 & 2 & - & - & - & 2 & 2 \\
\hline $\mathrm{PG}(\mathrm{ml})$ & 2 & 2 & 2 & - & - & 2 & 2 & 2 & - & - \\
\hline $\mathrm{SSG}(\mathrm{mg})$ & 3 & 3 & 3 & 3 & 3 & 3 & 3 & 3 & 3 & 3 \\
\hline Honey (ml) & 2 & 2 & 2 & 2 & 2 & 2 & 2 & 2 & 2 & 2 \\
\hline Water (ml) & 10 & 10 & 10 & 10 & 10 & 10 & 10 & 10 & 10 & 10 \\
\hline
\end{tabular}

The prepared films were evaluated for various parameters such as morphological and physicochemical parameters. All the formulated films had the uniform thickness and were transparent in nature. The films had smooth surfaces and they were elegant enough to appear. The thickness of the oral fast disintegrating films was measured by using a screw gauge and was varied from $0.127 \pm 0.012 \mathrm{~mm}$ to $0.163 \pm 0.052 \mathrm{~mm}$. The visual appearance data of the films were given in table 4 .

The surface $\mathrm{pH}$ of all the formulations was in the range of $5.42 \pm 0.320$ to $6.85 \pm 0.521$, these values were nearer to $\mathrm{pH}$ of the saliva. It indicated that the films were not causing any irritation in the oral cavity. Percentage moisture uptake by the films gives information about the stability of the films. All the formulations showed the moisture uptake value less than $2.5 \%$, it indicated that the formulations were stable. The films were subjected to the percentage moisture loss studies in order to know the amount of moisture present in the films after complete drying, which alters the stability of films. The results revealed that the loss of moisture was less and were not fragile in nature. Tensile strength indicates the ability of film to withstand rupture. The data of the study revealed that the values were between $1.45 \pm 0.01$ to $2.35 \pm 0.42 \mathrm{~cm}^{2}$. It 
indicated that the films have enough tensile strength and can withstand its structure during transportation $[29,30]$. The percentage elongation study reveals the elasticity and plasticity of the polymer and the data of the films was in the range of 1.5 to $7.6 \%$. The data revealed that by changing the polymer type and concentration the values were changing. Folding endurance gives an indication of the brittleness of the film. The brittleness of the film depends upon the concentration of hydrophilic polymer and plasticizer. The films exhibited the folding endurance values were above 250; it revealed that the films were non-brittle. The physicochemical evaluation data of the films was given in table 5 and 6.

Table 4: Morphological properties of herbal films

\begin{tabular}{lllll}
\hline S. No. & Formulation & Visual appearance & Surface $^{*}$ & Film forming capacity $^{*}$ \\
\hline 1 & F1 & Homogenous, transparent & Smooth & Very good \\
2 & F2 & Homogenous, transparent & Smooth & Average \\
3 & F3 & Homogenous, transparent & Smooth & Very Good tacky \\
4 & F4 & Homogenous, transparent & Smooth & Very good \\
5 & F5 & Homogenous, transparent & Smooth & Best \\
6 & F6 & Homogenous, transparent & Smooth & Average \\
7 & F7 & Homogenous, transparent & Smooth & Very good \\
8 & F8 & Homogenous, transparent & Smooth & Best \\
9 & F9 & Homogenous, transparent & Smooth & Best tacky \\
10 & F10 & Homogenous, transparent & Smooth & Average \\
\hline
\end{tabular}

*values are expressed as mean $\pm \mathrm{sd}, \mathrm{n}=3$

Table 5: Physico-mechanical properties of films

\begin{tabular}{|c|c|c|c|c|c|c|c|}
\hline S. No. & Formulation & $\begin{array}{l}\text { Thickness } \\
(\mathrm{mm} \pm \mathrm{SD})^{*}\end{array}$ & $\begin{array}{l}\text { \%elongation } \\
(\% \pm \text { SD) }\end{array}$ & $\begin{array}{l}\text { Folding } \\
\text { endurance* }\end{array}$ & $\begin{array}{l}\text { Weight } \\
\text { uniformity* }\end{array}$ & $\begin{array}{l}\text { Tensile } \\
\text { strength }\end{array}$ & Surfaces $\mathrm{pH}^{*}$ \\
\hline 1 & F1 & $0.127 \pm 0.012$ & $1.5 \pm 0.011$ & $>200$ & $3.52 \pm 0.041$ & $1.45 \pm 0.012$ & $5.32 \pm 0.051$ \\
\hline 2 & $\mathrm{~F} 2$ & $0.132 \pm 0.021$ & $2.3 \pm 0.015$ & $>250$ & $3.54 \pm 0.041$ & $1.63 \pm 0.018$ & $5.69 \pm 0.064$ \\
\hline 3 & F3 & $0.129 \pm 0.018$ & $1.8 \pm 0.013$ & $>270$ & $3.55 \pm 0.042$ & $1.85 \pm 0.021$ & $5.88 \pm 0.075$ \\
\hline 4 & $\mathrm{~F} 4$ & $0.153 \pm 0.032$ & $4.5 \pm 0.022$ & $>200$ & $3.57 \pm 0.042$ & $2.15 \pm 0.041$ & $5.54 \pm 0.031$ \\
\hline 5 & F5 & $0.123 \pm 0.010$ & $1.2 \pm 0.009$ & $>280$ & $3.63 \pm 0.046$ & $2.42 \pm 0.062$ & $6.08 \pm 0.090$ \\
\hline 6 & F6 & $0.134 \pm 0.024$ & $2.4 \pm 0.016$ & $>230$ & $3.65 \pm 0.046$ & $1.34 \pm 0.009$ & $6.25 \pm 0.092$ \\
\hline 7 & F7 & $0.182 \pm 0.051$ & $5.2 \pm 0.028$ & $>270$ & $3.73 \pm 0.050$ & $2.35 \pm 0.055$ & $5.90 \pm 0.082$ \\
\hline 8 & F8 & $0.193 \pm 0.058$ & $6.8 \pm 0.039$ & $>250$ & $3.81 \pm 0.051$ & $1.92 \pm 0.032$ & $6.32 \pm 0.95$ \\
\hline 9 & F9 & $0.183 \pm 0.052$ & $5.9 \pm 0.030$ & $>250$ & $3.83 \pm 0.052$ & $2.35 \pm 0.055$ & $6.55 \pm 0.125$ \\
\hline 10 & F10 & $0.195 \pm 0.060$ & $6.9 \pm 0.040$ & $>230$ & $3.85 \pm 0.052$ & $1.36 \pm 0.009$ & $6.58 \pm 0.127$ \\
\hline
\end{tabular}

*values are expressed as mean \pm sd, $n=3$

Table 6: Physico-chemical properties of formulated films

\begin{tabular}{lllll}
\hline S. No. & Formulation & \%Moisture uptake & \%Moisture loss $^{*}$ & Disintegration time (sec) $^{*}$ \\
\hline 1 & F1 & $2.041 \pm 0.056$ & $1.136 \pm 0.014$ & $61.2 \pm 0.132$ \\
2 & F2 & $2.145 \pm 0.071$ & $1.269 \pm 0.015$ & $57.3 \pm 0.128$ \\
3 & F3 & $2.052 \pm 0.074$ & $1.146 \pm 0.018$ & $27.3 \pm .0140$ \\
4 & F4 & $2.183 \pm 0.074$ & $1.312 \pm 0.016$ & $60.9 \pm 0.131$ \\
5 & F5 & $2.207 \pm 0.075$ & $1.450 \pm 0.017$ & $32.4 \pm 0.147$ \\
6 & F6 & $2.144 \pm 0.071$ & $1.132 \pm 0.013$ & $53.4 \pm 0.125$ \\
7 & F7 & $2.166 \pm 0.073$ & $1.045 \pm 0.010$ & $53.3 \pm 0.125$ \\
8 & F8 & $2.088 \pm 0.058$ & $1.430 \pm 0.016$ & $62.4 \pm 0.132$ \\
9 & F9 & $2.114 \pm 0.062$ & $1.224 \pm 0.015$ & $67.3 \pm 0.55$ \\
10 & F10 & $2.106 \pm 0.060$ & $1.515 \pm 0.020$ & $69.013 \pm 0.138$ \\
\hline
\end{tabular}

*values are expressed as mean \pm sd, $n=3$

The disintegration time of the films was measured by using a disintegration rate testing apparatus. The data revealed that all the films were disintegrated within the time range of 27.3-69.8 sec. It indicated that all the films disintegrated very quickly. Drug Content of all the films was measured by standard assay method by taking 10 individual samples as per the test procedure. A film of size $2 \times 2$ $\mathrm{cm}^{2}$ was cut and kept in $100 \mathrm{ml}$ of the volumetric flask containing solvent. This was then shaken in a mechanical shaker till it was dissolved to get a homogeneous solution and then filtered. The drug content was determined spectroscopically after appropriate dilution of the sample by measuring the absorbance at $221 \mathrm{~nm}$. The drug release study of the films was carried out by using a paddle-type dissolution rate testing apparatus. The drug release study was carried out at $50 \mathrm{rpm}$ for a period of $5 \mathrm{~min}$. The release data from the films revealed that the release was in an immediate manner. The dissolution profile of all the formulations was depicted in fig. 3.

Table 7: Stability studies of Eclipta Prostrate

\begin{tabular}{|c|c|c|c|c|}
\hline S. No. & Physical appearance* & Tackiness $^{*}$ & Film separation* & Disintegration* \\
\hline F3 & Very good & Non Tacky & Separates & $29.32 \pm 0.27$ \\
\hline $\mathrm{F} 4$ & Average & Non Tacky & Separates & $33.15 \pm 0.29$ \\
\hline F6 & Good & Tacky & Difficult to separates & NA \\
\hline
\end{tabular}

*values are expressed as mean \pm sd, $n=3$ 


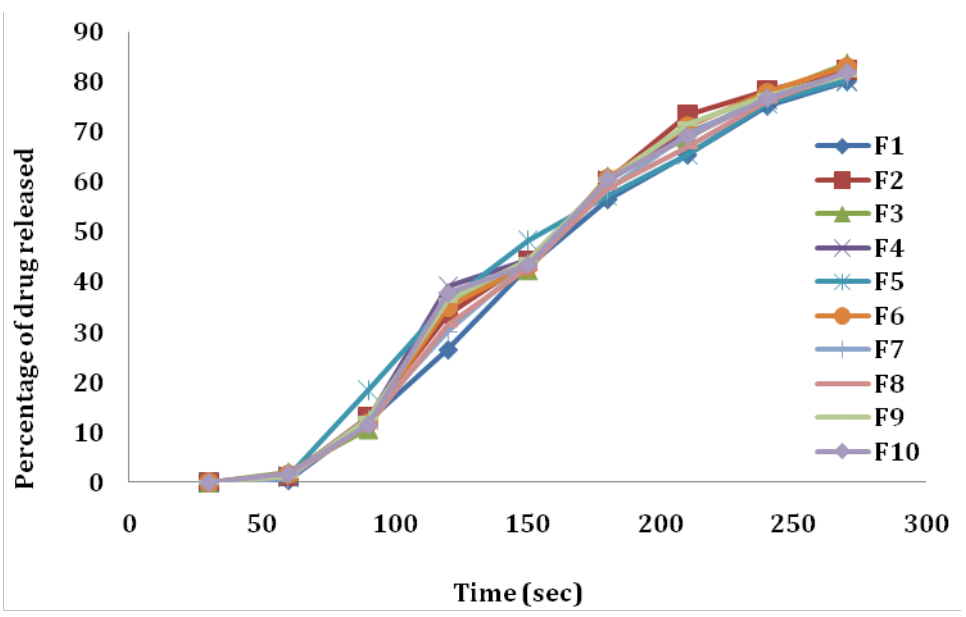

Fig. 3: In vitro release profile of fast dissolving films

The formulations were subjected to stability studies by storing them at $40 \pm 2{ }^{\circ} \mathrm{C}$ and $75 \pm 5 \% \mathrm{RH}$ for a period of $3 \mathrm{mo}$. The formulations were tested for various parameters after the test period. The data revealed that formulation F3 was stable throughout the period. The data were given in table 7 .

\section{CONCLUSION}

The objective of the present study was to fabricate and characterize the fast-dissolving herbal film of Eclipta Prostrate leaf extract for ulcer treatment. The aqueous extract of the leaves was collected by the soxhlation process. The phytoconstituents study of the extract revealed the presence of flavonoids, tannins and saponins which have anti-ulcer and antibacterial activity. The extract was formulated into films by solvent casting method with various polymers such as HPMC E5, HPMC E15, sodium alginate and PVA. The formulated films were subjected to physicochemical evaluation such as thickness, folding endurance, percentage elongation, moisture uptake, moisture loss, surface $\mathrm{pH}$ and drug release. All the formulations were good in appearance with smooth texture. The study revealed that out of the ten formulations F3 formulation showed fast disintegration, release, good appearance and stability. Based on the study results it can be concluded that Eclipta prostrate leaves extract can be effectively formulated in the form of oral films with expected patient compliance.

\section{FUNDING}

Nil

\section{AUTHORS CONTRIBUTIONS}

All authors have contributed equally.

\section{CONFLICT OF INTERESTS}

Declared none

\section{REFERENCES}

1. Patel J, Patel KR, Patel NM. Review on fast dissolving film. Int J Univers Pharm Bio Sci 2013;2:149-62.

2. Vijaya Sri K, Rohini P, Kamalakar. Montelukast sodium oral thin films: formulation and in vitro evaluation. Asian J Pharm Clin Res 2012;5:266-70.

3. Subash Vijaya Kumar, Basani Gavaskar, Guru Sharani, Y Madhusudan Rao. Overview on fast dissolving films; 2010;2:29-3.

4. Kamalesh Upreti, Lalit Kumar, Stutie Pathak Anand, Viney Chawla. Formulation and evaluation of Mouth dissolving films of paracetamol. Int J Pharm Pharm Sci 2014;6:200-2.

5. Shaikh S, Shete A, Doijad R. Formulation and evalution of pharmaceutical aqueous gel of powdered guava leaves for mouth ulcer treatment. Pharma Tutor 2018;6:32-8.

6. Shivaji SAK, Vaibhav RV. Formulation and development of quercetin and monoammonium glycyrrhizinate loaded gel for the treatment of mouth ulcer disease. Int J Pharm Sci Res 2021;12:1789-98.

7. Rownak Jahan, Abdullah A, Snehali M, Mohammed R. Ethnopharmacological significance of Eclipta alba Hassk. Int Scho Res Not 2014;38:22-6.

8. Sivaranjani R, Ramkrishnan K. Traditional uses of medicinal plants in treating skin diseases in Nagapattinam district of Tamilnadu. Int Res J Pharm 2012;3:201-4.

9. Nishimura M, Matsuura $K$, Tsukiko $T$, Yamashita $H$, Inagaki $N$, Sugiyama $\mathrm{T}$, et al. In vitro and in vivo characteristics of prochlorperazine oral disintegrating film. Int $\mathrm{J}$ Pharm 2009;368:98-102.

10. Mashru RC, Sutariya BC, Parikh PP. Development and evaluation of fast dissolving films of salbutamol sulphate. Drug Dev Ind Pharm 2005;31:25-4.

11. Patel Priti, Patel Jaymin, Patel Kaushika, Nihar Shah, Shah Shreeraj. A review on fast dissolving sublingual film. J Pharm Sci Bio Sci Res 2015;5:279-85.

12. Granfors MT, Backman JT, Laitila J, Pertti JN. Tizanidine is mainly metabolized by cytochrome P450 1A2 in vitro. Br J Clin Pharmacol 2004;57:349-53.

13. Rajini Bala, Shailesh Sharma. Formulation optimization and evaluation of fast dissolving film of aprepitant by using design of experiment. Bull Faculty Pharm Cairo University 2018;56:159-68.

14. Raghuraman S, Ravichandran V, Shaffina SH, Rajasekaran T, Benito Johason D, Sankar V. Design and evaluation of propranolol hydrochloride buccal films. East Pharm 2001;10:109-11.

15. Mona Nagar, Mayank Nagar, Vikram Chopra. Formulation and evaluation of mouth dissolving film of antipsychotic drug aripiprazole. Der Pharm Lett 2012;4:1221-7.

16. Shivani Singh, Satyam Gangwar, Garima Garg, Vipin Garg, Sharma PK. Formulation and evaluation of rapidly disintegrating film of levocetirizine hydrochloride. Der Pharm Lett 2010;2:434-9.

17. Priyanka Nagar, Chauhan, Mohd Yasir. Insights into polymers: film formers in mouth dissolving films. Drug Inv Today 2011;3:280-9.

18. Rajni Bala, Pravin Pawar, Sushi Khanna, Sandeep Arora. Orally dissolving strips: a new approach to oral drug delivery system. Int J Pharm Invest 2013;3:67-6.

19. Smart JD. Buccal drug delivery. Exp Open Drug Delivery 2005;2:507-17.

20. Kadam VS, Bharkad VB, Shete GA, Jameel A, Shendarkar GR, Jadhav SV. Formulation and evaluation of fast dissolving oral film of metoclopramide HCl. W J Pharm Pharm Sci 2008;6:2052-66.

21. Ramani Gade, Aparna Aynampudi, Anitha Makineni. Design and development of pravastatin sodium fast dissolving films from natural mucilage of ocimum bacilicum seeds. Int J Pharm Res Rev 2014;3:17-7.

22. Swamy, Shiva Kumar S. Formulation and evaluation of fast dissolving oral films of palonosetron hydrochloride using HPMC-E5. Int J Pharm Chem Sci 2015;8:23-9. 
23. Pallavi K, Pallavi T. Formulation and evaluation of fast dissolving films of eletriptan hydrobromide. Int J Curr Pharm Res 2018;9:13-1.

24. Rawda Khalifa Ali, Shabaraya AR, Mohd Azharuddin. Design and evaluation of fast dissolving oral films of granisetron hydrochloride. Am J Pharm Tech Res 2012;2:590-601.

25. Desai P, Basu B. Design and evaluation of fast dissolving oral films of domperidone. Int Res J Pharm 2012;3:134-45.

26. Udayashankar AC, Nandhini M, Rajini SB, Prakash HS Pharmacological significance of medicinal herb Eclipta alba L.-a review. Int J Pharm Sci Res 2019;1:3592-606.
27. Murata Y. Preparation of fast dissolving films for oral dosage form natural polysaccharides. Materials 2010: 3:4291-9.

28. Bhupinder B, Sarita J, Mandeep K, Harmanpreet S. Orally fast dissolving films: innovation in formulation and technology. Int J Pharm Sci Rev Res 2010;9:50-7.

29. Desai P, Basu B. Design and evaluation of fast dissolving oral films of domperidone. Int Res J Pharm 2012;3:134-45.

30. Vaishali YL, Kashmira BU. Formulation development and evaluation of fast dissolving film of telmisartan. Ind J Pharm Sci 2012;15:132-7. 